\title{
3D Reproductions of Cultural Heritage Artefacts: Evaluation of significance and experience
}

\author{
UMAIR SHAFQAT MALIK, Politecnico di Milano, Italy \\ LISELORE N.M. TISSEN, Leiden University, Netherlands \\ ARNOLD P.O.S. VERMEEREN, TU Delft, Netherlands
}

\begin{abstract}
3D digitization of cultural heritage has long been used to preserve information about cultural heritage $(\mathrm{CH})$ objects such as architecture, art, and artifacts. 3D dissemination of $\mathrm{CH}$ objects through technologies such as augmented reality, virtual reality, and 3D printing have impacted the fields of art history and cultural heritage and have become more common. Yet, studies that go beyond the technical aspects of 3D technology and treat such topics as their significance for restoration, conservation, engagement, education, research, and ethics hardly exist. The aim of this paper is twofold: on the one hand, it aims to get a better understanding of the applicability of each technology for different purposes (education, research, conservation/restoration, and museum presentation), and, on the other hand, it focuses on the perception of these technologies. This research was carried out by combining a literature review with quantitative and qualitative analyses of the data acquired through (1) a questionnaire of eleven questions and (2) a workshop with a group of specialists and non-specialists who were asked to brainstorm about the different uses of the 3D technologies and their applicability to their areas of work and research. Based on the analysis of these quantitative and qualitative data, we provide some criteria for using 3D digitized and printed reproductions to enhance cultural experiences. The results demonstrate the importance of carefully designing 3D interactions in the personal and cultural contexts of end-users and cultural institutions in order to create authentic cultural experiences.
\end{abstract}

Keywords:

Digital heritage, 3D reproductions, Art perception, Museum experience design, 3D replicas, Virtual Reality, Augmented reality, 3D printing

SDH Reference:

Umair S. Malik, Liselore N.M. Tissen, Arnold P.O.S. Vermeeren. 2021. 3D Reproductions of Cultural Heritage Artefacts: Evaluation of significance and experience. SDH, 5, 1, 1-29.

https://doi.org/10.14434/sdh.v5i1.32323

\section{INTRODUCTION}

In recent years, three-dimensional technologies have been adopted in many fields. They offer the possibility of physically or digitally reproducing nearly any object, no matter its size, material, or

Author's address: Umair Shafqat Malik, Department of Design, Politecnico di Milano, Via Giovanni Durando, 38/a, 20158 Milano, Italy; email: umairshafqat.malik@polimi.it; Liselore Tissen, Centre for the Arts in Society, Leiden University, P.N. van Eyckhof 2, 2311 BV Leiden, Netherlands; email: l.n.m.tissen@hum.leidenuniv.nl; Arnold P.O.S. Vermeeren, Faculty of Industrial Design Engineering, TU Delft, Landbergstraat 15, 2628 CE Delft, Netherlands; email: a.p.o.s.vermeeren@tudelft.nl

(C) 2021 by the authors; licensee Studies in Digital Heritage, IU, Bloomington (IN), USA. This article is an open access article distributed under the terms and conditions of the Creative Commons Attribution License (CC BY-NC) 
shape (3D reproductions). The opportunities offered by 3D printing and digital technologies such as augmented reality (AR), virtual reality (VR) as well as digital screen displays have become a topic of interest, particularly in the fields of cultural heritage $(\mathrm{CH})$ and museum practice. Disasters such as the fire in the Notre Dame cathedral in Paris (2019) and the Islamic State's destruction of archaeological sites, notably in Palmyra (2015-16), highlight the fragility of our heritage. It is precisely here that technology can offer ways of reviving and preserving material qualities of artifacts, works of art made of fragile materials, and objects in museum collections [De Luca 2020; Denker 2017]. Over the years, 3D digitized and 3D printed models of $\mathrm{CH}$ objects have been created during the restoration and reconstruction of works of art [Acke et al. 2021]. Not only are these technologies promising for the conservation and preservation of our heritage, but it has also become apparent that engaging with and researching works of art today without the help of 3D reproduction is less and less common. The facility with which artworks can be used, adjusted and distributed via these technologies promotes much greater accessibility and stimulates a richer array of experiences than would have been possible in a traditional museum setting. Similarly, to carry out the fundamental educational role of museums [Hooper-Greenhill 1999], the use of digital and physical replicas has been widely recognized in literature [[CECA 2014; Freeman et al. 2016]CECA 2014; Freeman et al. 2016; Antonaci et al. 2013; Fatta et al. 2018]. In this paper, we survey the applicability of 3D replicas to museum education, museum presentation, research, conservation, and restoration.

As the world's art and $\mathrm{CH}$ objects become digitized and widely available to us thanks to these methods of 3D reproduction, we have started to look at artworks differently as they have become accessible beyond the physical confines of a museum's walls. Technology reshapes the engagement with and the perception of these objects as it provides possibilities and new opportunities hitherto unimaginable. This inevitably affects our perception of art and cultural heritage artifacts. When speaking of the perception of art, we refer to the complex multifaceted relationship between the work of art as a visual starting point and the viewer's personal understanding of and emotional connection to it. Furthermore, these potential shifts in the perception of art will evidently have its effects on how the viewer understands the authenticity, originality and genuineness of an artwork. Authenticity is a complex term capable of being interpreted in several ways depending on such factors as a person's (cultural) background, religion, ethnicity, gender, and age. From the Western perspective from which we are conducting this research, authenticity of an artwork is oftentimes sought in its tradition of creation and is proved by its use of genuine materials. Needless to say, 3D reproductions fall outside what can be considered authentic in this sense [Khunti 2018]. Yet, if we consider the fact that art's value does not solely rely solely on its static materials but also on its contextual and conceptual meaning, we may rightly insist that authenticity arises from both an object's material qualities and also its more conceptual and intangible interpretative perspectives. With this background in mind, we are in a position to understand the impact of these technologies on our perception of art and to grasp the significance and applicability of these technologies in museums and other $\mathrm{CH}$ fields.

This paper aims to provide a better understanding of the perception of various methods of digital and physical 3D reproduction (AR, VR, digital screen displays, 3D printing) and to evaluate their applicability. Furthermore, it sheds light on the ethical consequences of the introduction of these reproduction methods in the field of art and $\mathrm{CH}$ by analyzing the impact of these technologies on our perception of art. Although this study focuses on museums, the results could be considered helpful 
for the $\mathrm{CH}$ field more generally. This paper offers an exploratory investigation with an interdisciplinary approach focusing on analyzing the perception of reproductions among different stakeholders (designers, art historians, museum visitors, engineers) and for various purposes (education, research, conservation/restoration, and museum presentation). Furthermore, it uniquely tries to bring together the reflections of various stakeholders in a single study. On the basis of the analyses of data collected from the stakeholders (both professionals directly working with CH objects as well as non-specialists indirectly engaging with art), this paper proposes ways in which 3D technologies can enhance cultural experiences in a way that respects the material and conceptual integrity of the original object and its creators.

The main questions we address are:

1. How are the methods of 3D reproduction under study (AR, VR, digital screen displays, 3D printing) perceived on their own and in comparison to each other?

2. In what way can methods of $3 \mathrm{D}$ reproduction contribute to the experience of $\mathrm{CH}$ objects and artworks for museum education, $\mathrm{CH}$ research, conservation/restoration and museum presentation?

3. What are the design factors to be considered in order to develop enhanced experiences and interactions with 3D digitized and printed $\mathrm{CH}$ objects in a museum setting?

To answer these research questions, we have combined existing data presented in the literature with quantitative and qualitative analyses of data collected from stakeholders for creating evaluation criteria of experience with 3D reproductions. This research provides a contemporary evaluation of 3D reproductions. Museums can employ this evaluation to reconsider the use of 3D digitization and physical reproduction in fulfilling their mission and in creating new narratives in a world that imposes limits on the physical interactions permitted with works of art as well as museums themselves.

\section{STATE OF THE ART: LITERATURE REVIEW AND CURRENT TRENDS}

During the past 25 years, early experiments [Levoy et al. 2000; Godin et al. 2002; Guidi et al. 2004], developments in digital photography, and automatization of algorithms for feature extraction from images [Lowe 1999; Lowe 2004; Yan Ke and Sukthankar 2004; Bay et al. 2006] led to a new role of image-based 3D modeling in several areas including CH documentation [Pieraccini et al. 2001; Guidi et al. 2009]. Based on these developments, several museums started to experiment with 3D digitization of a limited set of objects [Bernardini et al. 2002; Levoy 1999; Atzeni et al. 2001; Bryce 2015]. Following these projects, a few large-scale initiatives for 3D digitization of collections of archeological artifacts were started worldwide: the European project 3DICONS [Guidi et al. 2013], the UCL's Petrie Museum of Egyptian Archaeology [Robson et al. 2012], and the Smithsonian 3D digitization [Smithsonian's Digitization Program Office 2013] to name a few. More recently, thanks to the sponsorship of Indiana University, the Uffizi Gallery in Florence started the three-dimensional digitization of its complete collection of sculptural heritage [Guidi et al. 2018]. Despite their

usefulness, these projects have not focused on enhancing experiences with the 3D reproduction of $\mathrm{CH}$ assets for the purposes defined in the introduction. 
The International Council of Museums (ICOM) [ICOM 2021] defines a museum as "a non-profit, permanent institution in the service of society and its development, open to the public, which acquires, conserves, researches, communicates and exhibits the tangible and intangible heritage of humanity and its environment for the purposes of education, study and enjoyment." Therefore, museums are not solely interested in digitizing their collections in order to create repositories of digital replicas, but they are also eager to use these technologies to promote and raise public awareness about the treasures housed in their collections. Therefore, digitization projects should be more directed towards goals such as (1) attracting visitors to the museum to view the physical $\mathrm{CH}$ assets and not just to see their virtual replicas online; (2) preserving the diversity of values that can be attributed to heritage [Szmelter 2013], which does not solely rely on its materials and appearance but also on the integrity of all its components and its intangible qualities; (3) assisting specialists of different fields working with $\mathrm{CH}$ objects by merging interdisciplinary data on one platform. However, most of the literature about these 3D technologies for $\mathrm{CH}$ focus on either the technical aspects or how the quality of the replications can be altered to achieve perfection [Remondino 2011; Malik and Guidi 2018; Balletti et al. 2018].

Recently, in museum research, "the digital" and the digitization of $\mathrm{CH}$ has started to become the new norm. This concept has been defined in the context of the post-digital museum [Parry 2013]. The consequences of the introduction of post-digital media on museum studies have been largely studied within the fields of museum design and visitor experience [Mason 2020]. Although these studies have contributed to revealing the importance of 3D replicas in contemporary museum research, the specific applications of 3D replicas, their implementation and perception have not been investigated thoroughly. The role of reproductions and their possible usefulness in conservation and museum studies is often ignored, and the possible consequences for museums are unexplored. Important theorists within museum discourse such as [Hooper-Greenhill 2013; Dudley 2013; McClellan 2008; Macdonald et al. 2015] rarely if ever write about the role of reproductions in material, visual and living culture. Although the reproduction of art is more often treated in conservation studies than it is in museum studies, the literature is still scarce [Viñas 2002; Scott 2016] and work published to date does not consider more contemporary 3D reproduction technologies (AR, VR, 3D printing and digital screen displays) in relation to restoration and conservation.

From the perspective of museum presentation, starting from the classical museum experience model [Dierking and Falk 1992], the literature suggests the importance of new ways afforded by digital technology to interact with visitors [Vermeeren et al. 2018; Freeman et al. 2016]. Recently, there has been an increase in studies that analyze the possibilities of 3D technologies for experiences in museums, but most of these studies remain focused on studying a single aspect of the experience: co-designing with technology [Ciolfi et al. 2015], personalization [Ardissono et al. 2012] and use of 3D reconstructions for interactive museum experiences (tangible and intangible) [Petrelli et al. 2014; Duranti 2017; Petrelli 2019].

Similarly, the influence of digital technologies is often discussed in publications on museum learning and education [Menano et al. 2019; Liguori and Rappoport 2018; Alexandri and Tzanavara 2014]. The M3 learning model [Vavoula and Sharples 2009] evaluates the usefulness and effects of mobile technologies in terms of learning in museums, its implementation, and its long-lasting effects. This model can also be applied to improve the digital literacy of $\mathrm{CH}$ professionals as is 
explored in a recent British project, "One by One" [Barnes et al. 2018]. Yet, the importance of digital technologies in museums is highlighted in these studies without specifically focusing on the reproduction of $\mathrm{CH}$ objects.

Furthermore, within the studies that do focus on reproductions of $\mathrm{CH}$, there still is a division between digital versus physical methods of replication [Di Giuseppantonio Di Franco et al. 2018; Neumüller et al. 2014; Lowe 2020]. Studies that do analyze multiple technologies are mainly invested in establishing the "dos and don'ts" of experimenting with a method of 3D reproduction, studying technical limits, and often do not offer a deep investigation of the impact these technologies have on our perception of art or on the sense of authenticity, or "aura," we experience when interacting with art [Callet 2014].

Recent publications fail to treat the significance of 3D reproduction for restoration, conservation, participation, education, art history, and the authentic experience. As far as we know, there is no single comprehensive study that examines and compares the use of different physical and digital 3D reproduction technologies for various purposes as well as the implications of these technologies on the authenticity of the experience of art.

This scarcity motivated us to undertake field research in which Dutch professionals - curators, directors and restorers - and non-professionals were interviewed about their perspectives on the introduction of 3D reproduction [Tissen 2018]. Despite our interviewees' familiarity with 3D reproduction and art replication, we documented a restrained attitude towards 3D replication of art leading to a rejection of the technique. The possible importance of 3D reproduction for museums was therefore left undiscovered. Yet, now in times of COVID-19, in which we all have to deal with museums and their collections more remotely, it has become of increasing importance to research the impact and usefulness of these technologies.

\section{CASE STUDIES}

In order to carry out our research and promote discussions on the use of 3D reproductions for $\mathrm{CH}$ objects, case studies were used. The main case study - Laocoön and His Sons - was presented by means of various 3D reproduction methods. In addition to this case study, we also used these previous projects: a video showing a 3D reconstruction of a Roman circus in Milan 286-402 AD, and a VR presentation of Leonardo da Vinci's Last Supper (1495-1498). These examples helped by broadening the ways of presenting and interacting with the technologies under study. They also made it possible to include various types of $\mathrm{CH}$ artifacts, ranging from grand architectural scale models to sculptures and paintings.

\subsection{Digital touch screen, AR and 3D printing}

The Roman statue Laocoön and His Sons (probably dating to the first century BCE and excavated in Rome in 1506) was selected as the central case study of this research. It was presented by means of various methods: an interactive digital touch screen, a mockup AR application created specifically for this research project, and a high-quality polychrome 3D print. The statue used in the case study is a copy of the original Roman statue (Vatican Museum in Rome) made by the Florentine sculptor

Studies in Digital Heritage, Vol. 5, No. 1, Publication date: June 2021 
Baccio Bandinelli in 1520. It is currently on display at the Uffizi Gallery Museum in Florence (Figure 1a). A 3D digitized model of high resolution geometry and texture was created through the auspices of the Indiana University-Uffizi 3D Digitization Project ${ }^{1}$.

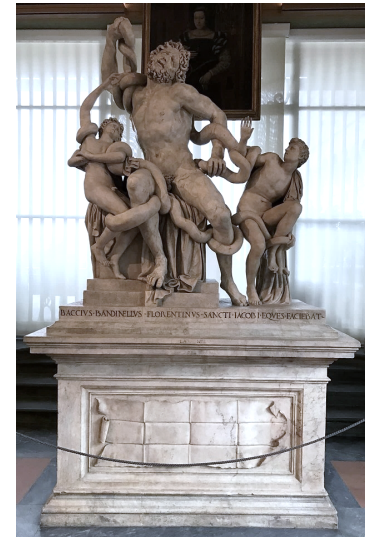

(a)

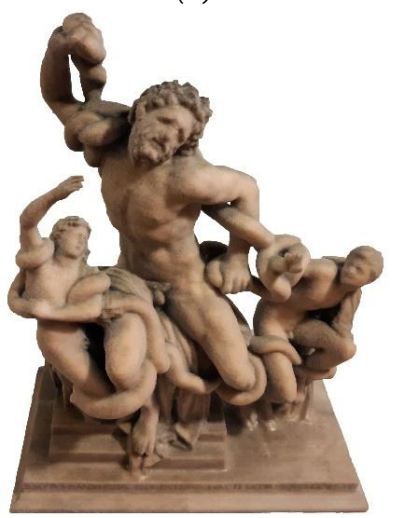

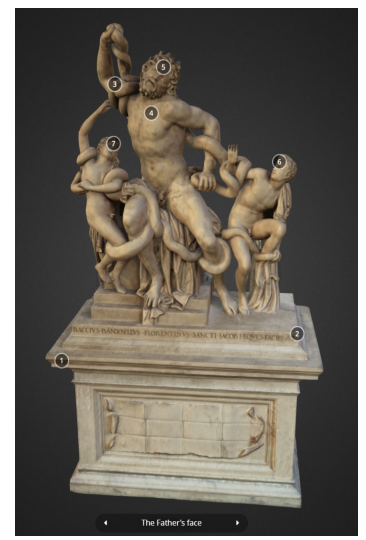

(b)

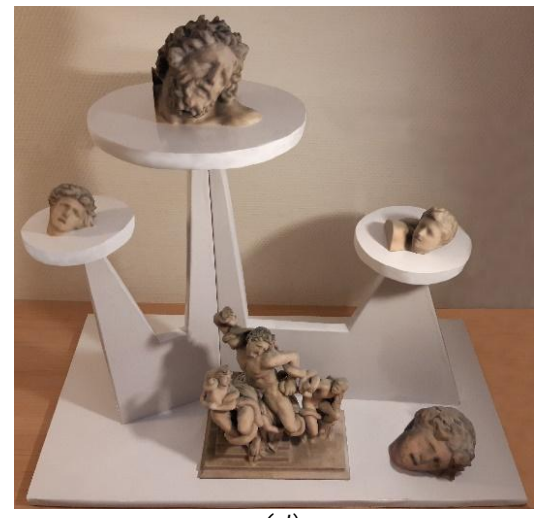

(d)
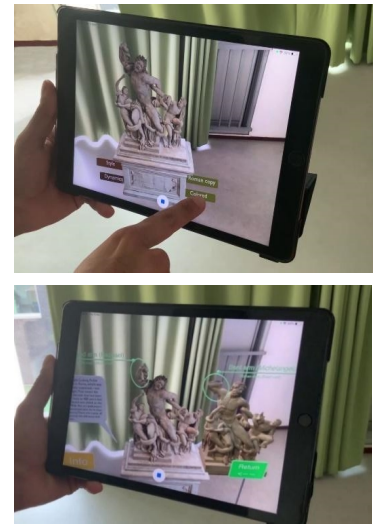

(c)

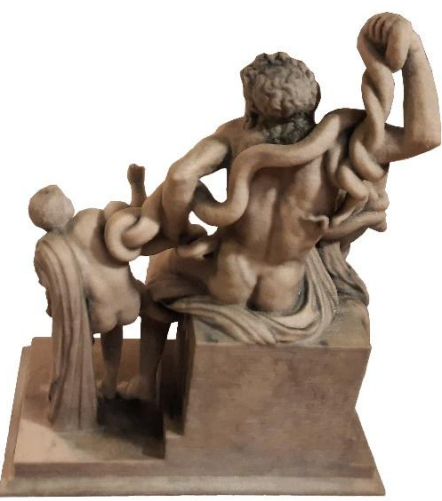

Figure 1. Laocoön and His Sons: (a) by Baccio Bandinelli, 1520-1525, Marble, $208 \mathrm{~cm} \times 163 \mathrm{~cm} \times 112 \mathrm{~cm}$, Uffizi, Florence, Italy and a 3D model of the statue presented in different ways: (b) an annotated model on Sketchfab through a digital touch screen; c) through a mockup AR application with audio descriptions, written panels, other models for comparison and 2D animations; (d)-(f) 3D prints in high resolution and full colors produced by scaling up and down some important features.

When showing the statue via a digital touchscreen, the high-resolution model was presented using Sketchfab - a web service for sharing and visualizing 3D models. The 3D model included the traditional information provided for a work of art (name, artist, date, material, dimensions, principal restorations and bibliography) as well as the technical metadata about the author of the model and

${ }^{1}$ The 3D digitization of ancient sculptures owned by the Uffizi Gallery was sponsored by Indiana University (USA) and included collaboration with the Polytechnic University of Milan and the advice of a scientific committee of experts in the fields of art history and archaeology from Emory University, Indiana University, and the University of Florence. For details see: http://www.digitalsculpture.org/florence/ 
the way 3D data was captured. Furthermore, location-based annotations were added to the 3D model in order to clarify aspects of the statue and to be able to connect narratives belonging to the depicted story $^{2}$. Owing to the high-resolution geometry and texture of the model integrated with the annotations, the user could navigate around the model, zoom in on details and explore both the formal and narrative information in a way which is not possible in a usual museum setting (Figure 1b).

A mock-up AR application was also created. The same 3D model of the statue was integrted with other 3D models, text/audio narratives, and educational animations (Figure 1c). The application could be navigated and used by superimposing the virtual model onto any plane surface or a predefined anchor point where the user sees four different tabs: style, movement, comparison, and colors. The style tab transfers the users to a locale where they can learn more about the unique artistic style of the statue by comparing it to similar artworks. Furthermore, through 2D animations, this tab highlights some important details on the sculpture. Similarly, the movement tab makes the user focus on the sense of movement present in the sculpture through its composition. The color tab superimposes digitally created colors over the 3D model in the augmented environment ${ }^{3}$. The comparison tab creates a narrative by comparing the Renaissance version with a 3D model of the original Roman sculpture. Through this ability to compare and interactive storytelling, the user could learn about the history and lifecycle of the statue, the discovery of the Roman statue in the 16th century, the restorations and the several copies of the statue created at different periods in time. All of these tabs included text instructions and audio narratives ${ }^{4}$.

The digital model of this statue was slightly altered so that it could be 3D-printed in full color at a scale of 1:10. Additionally, the most important features of the sculpture, i.e., the heads of Laocoon and his sons, were then printed on a scale five times larger than the 3D print of the complete statue (Figure 1d). These features were placed on a stand that was made to mimic the composition of the statue. By doing so, different possibilities of interaction with physical 3D replicas were demonstrated to the users. The technology used for 3D printing was Colorjet sandstone printing ${ }^{5}$.

\subsection{Video on digital screen}

An additional project familiarized the participants with showing a video on a digital screen without any (direct) user interaction. In this video, the viewer was guided through the steps, procedures, methodological approaches and workflow for diachronically reconstructing a lost monument, i.e., a late Roman circus in the city of Milan. Today, the circus is completely buried under the modern city.

\footnotetext{
2 https://sketchfab.com/3d-models/laocoon-and-his-sons-b6d161aa6d0e426dacc9899a7836elc5

${ }^{3}$ Even though no colors were found by polychromy analysis performed on this statue, the colored sculpture presented in this application was based on an artistic representation of Laocoön group in a painting by a Florentine painter Alessandro Allori in the 16 th century.

4 The application was created using the AR Creation Tools from Apple, which includes Reality Composer, Xcode, Reality Converter and USDZ Tools. https://developer.apple.com/augmented-reality/tools/

${ }^{5}$ The printer used was a ProJet CJP 660Pro - an industrial full-color 3D printer with a resolution of 600 x 540 dpi made by 3D Systems. https://www.3dsystems.com/3d-printers/projet-cjp-660pro
} 
The approaches of diachronic 3D reconstruction and heterogeneous data integration were used to show the monument in its current state and with its presumed past appearance [Micoli et al. 2018]. ${ }^{6}$

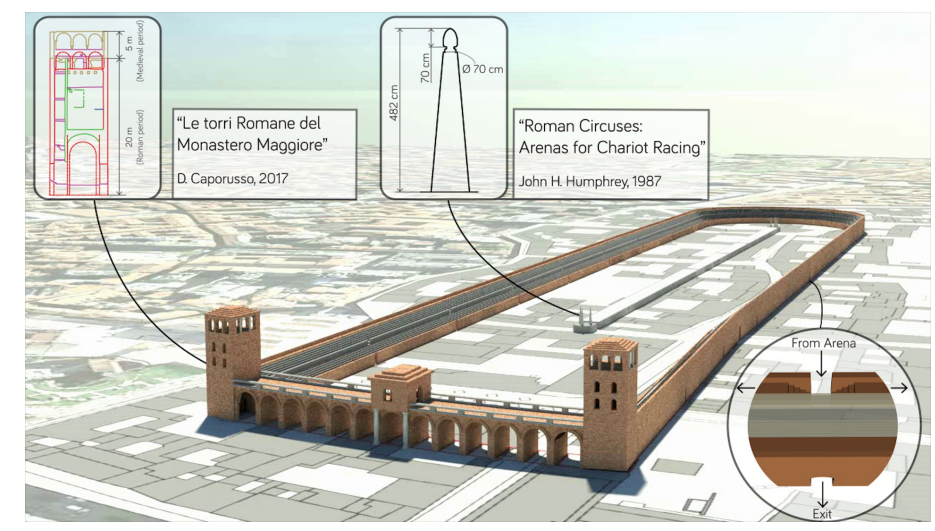

Figure 2. A snapshot of the video representing the data integration from different sources for reconstructing a lost Roman circus in Milan presented on a digital screen.

\subsection{VR application}

The second additional application ran on a VR headset, making it possible for the users to visit and explore a place inaccessible to them in reality. The selected project is the Last Super Interactive (LSI), which is a VR application that combines experimental digital narratives and virtual storytelling with immersive technologies based on The Last Supper, a late 15th century mural painting by Leonardo da Vinci located in the refectory of the Convent of Santa Maria delle Grazie in Milan. This project explores the effectiveness of 3D reproductions in creating immersive virtual narratives. The LSI application allows users to view the painting from multiple viewpoints and perspectives in order to gain a better understanding of how linear perspective was used by Leonardo. The accurate representation of the $2 \mathrm{D}$ painting in a three dimensional way enables visitors to virtually immerse themselves in the painting. Users can not only visit refectory, but they can also learn about the historical context of the painting through a story connected through the surrounding environments where Leonardo created his masterpiece [Fischnaller 2018]. ${ }^{7}$

\section{METHODOLOGY}

The goal of this study was to provide a useful basis for designing interactive experiences through 3D reproductions of $\mathrm{CH}$. For this reason, various data were collected through a collaborative workshop involving all the stakeholders of this research. The collected data include: user experience with 3D reproductions, the interaction between user - object - reproduction, the perception of various 3D

\footnotetext{
${ }^{6}$ The research for this project was carried out in the framework of the project Cultural Heritage Through Time - CHT2, funded by the Joint Programming Initiative on Cultural Heritage (JPI-CH), supported by the Italian Ministry for Cultural Heritage (MiBACT), the Italian Ministry for University and Research (MIUR), and the European Commission. http://cht2-project.eu/

7 The 3D survey was carried out for the first time for the monastery by the Department of Mechanics of Politecnico di Milano, allowing to reconstruct the original path from the square to the interior of the church, to the cloister, and to the cenacle room.
} 
reproduction methods, the existing practices within the field, new approaches for the use of various reproduction methods, and the implications of these technologies' introduction into the fields of art and $\mathrm{CH}$. The initial proposal was to organize a workshop for the stakeholders. This was planned by hosting several activities that included (physical) interaction of participants with the 3D reproductions as described above and the collection of data through creative sessions and recordings of conversations and discussions. However, owing to the restrictions imposed by COVID-19, the workshop had to be held online.

\subsection{Stakeholders}

A total of 27 stakeholders with different backgrounds were invited to participate in the workshop. Based on their experience and specialties, the participants were divided into four groups, each with at least six people. Given the fact that the workshop was held online, we could invite more people from different backgrounds. The four groups of participants with their specialties/backgrounds are reported in Table 1.

Table 1. List of participants of the workshop with their background.

\begin{tabular}{|c|c|c|c|c|c|c|c|}
\hline \multicolumn{2}{|r|}{$\begin{array}{l}\text { Designers } \\
\text { (Group 1) }\end{array}$} & \multicolumn{2}{|r|}{$\begin{array}{l}\text { Art historians / Archeologists } \\
\text { / Museum professionals (Group 2) }\end{array}$} & \multicolumn{2}{|r|}{$\begin{array}{l}\text { Digital application experts / } \\
\text { Engineers (Group 3) }\end{array}$} & \multicolumn{2}{|r|}{$\begin{array}{l}\text { Museum visitors } \\
\text { (Group 4) }\end{array}$} \\
\hline 1 & Color design researcher & 1 & Art historian & 1 & 3D applications researcher & 1 & Arts student \\
\hline 2 & $\begin{array}{l}\text { Design education } \\
\text { researcher }\end{array}$ & 2 & Museum studies researcher & 2 & $\begin{array}{l}\text { Professor of reverse } \\
\text { engineering }\end{array}$ & 2 & Art dealer \\
\hline 3 & $\begin{array}{l}\text { Senior lecturer in } \\
\text { Design }\end{array}$ & 3 & Lecturer in art history & 3 & $\begin{array}{l}\text { Digital museum } \\
\text { exhibitions researcher }\end{array}$ & 3 & $\begin{array}{l}\text { Computer } \\
\text { scientist }\end{array}$ \\
\hline 4 & $\begin{array}{l}\text { Museum experience } \\
\text { researcher }\end{array}$ & 4 & Museum Professional & 4 & $\begin{array}{l}\text { Professor of 3D printing for } \\
\text { arts }\end{array}$ & 4 & $\begin{array}{l}\text { Urban science } \\
\text { researcher }\end{array}$ \\
\hline 5 & $\begin{array}{l}\text { Industrial Design } \\
\text { graduate }\end{array}$ & 5 & $\begin{array}{l}\text { Museum innovation } \\
\text { Professional }\end{array}$ & 5 & $\begin{array}{l}\text { Digital heritage } \\
\text { Researcher }\end{array}$ & 5 & $\begin{array}{l}\text { Architecture } \\
\text { researcher }\end{array}$ \\
\hline 6 & $\begin{array}{l}\text { Interaction Design } \\
\text { researcher }\end{array}$ & 6 & Digital archeology professor & 6 & $\begin{array}{l}\text { Digital applications } \\
\text { student }\end{array}$ & 6 & $\begin{array}{l}\text { Architecture } \\
\text { researcher }\end{array}$ \\
\hline & & 7 & Art restorer & 7 & 3D printing professional & & \\
\hline & & 8 & Art restorer & & & & \\
\hline
\end{tabular}

\subsection{Pre-workshop meetings}

Just as the participants differed in age, background and experiences, so, too, they differed in their knowledge of 3D reproduction methods and their use. Therefore, they were invited to individual introductory meetings (lasting 30 to 45 minutes each) before the actual workshop took place. The purpose of these meetings was to maximize the efficiency of time available during the workshop by preparing the participants for the topic of discussion and their mutual collaboration using online platforms. During these meetings, the participants were introduced to Miro - an online visual 
collaboration platform for teamwork. ${ }^{8}$ They were provided with guidelines for collaborating in teams using this platform.

The different ways of presenting $\mathrm{CH}$ via 3D reproduction methods (section 3), were also demonstrated during these preparatory meetings. As the workshop was organized online, the participants could not physically interact with the 3D artifacts. Therefore, the pre-recorded videos of the researchers interacting with digital applications (AR, VR, digital screen displays) and 3D printed models were shared with all the participants. This way, they had the opportunity to view and analyze them before the workshop.

After the introductory meeting, the participants were asked to sign a digital form of consent, as the discussions were recorded for later analysis. They were also asked to fill in a questionnaire before the workshop. This questionnaire consisted of eleven questions which could be answered by scoring on a scale of 1-5, in which 1 signified least likely and 5 signified most likely. The questionnaire's purpose was to understand the general interest of the participants in 3D replicas presented through both digital and physical means. The questionnaires also helped us to analyze and understand the opinions and perceptions of participants on the proposed uses of 3D reproductions based on their experience of the introductory meetings before the workshop commenced.

\subsection{Workshop format}

During the workshop, all participants were simultaneously connected via Zoom meetings ${ }^{9}$ and Miro. In order to invite enough people to participate and hold their attention during the workshop, the total time for the workshop was set to two hours. The time was divided into an introductory session, two collaborative sessions with a five minute break between them, and concluded with a wrap-up and general conclusions. The introductory session lasted 15 minutes and included the individual introduction of the researchers, an introduction to the format of the workshop, the aims and goals of the activity, an overview of the research questions, the methodology for evaluating the collected data, and a brief introduction of the four groups of participants. In this first session, the participants were also informed about how the results were to be published afterward and the way they could access them.

The first collaborative session (lasting 15 minutes) was designed to quantitatively analyze different scenarios in the fields of art and $\mathrm{CH}$ for which 3D reproductions could be used through different methods (AR, VR, digital screens, 3D printing). Without dividing the participants into groups, everyone was asked to fill in at least four sticky notes (one of each color) on the Miro platform (Figure 3). The sticky notes were color-coded based on the purpose they served (blue = art conservation, yellow = education, green = museum presentation, pink = research/exploration, orange $=$ other $)$. On each sticky note, one could describe a method for using 3D reproductions and a scenario in which they thought the chosen reproduction technology could serve the purpose. The participants could fill in as many sticky notes as they wanted, with a minimum of 4 (1 art conservation, 1 education, 1 museum presentation, 1 research/exploration); the orange sticky notes were, of course, optional.

\footnotetext{
${ }^{8}$ https://miro.com/

${ }^{9}$ https://zoom.us/
} 
Before the start of the first session, instructions were given to the participants about what was expected of them and how they ought to fill in the sticky notes. These instructions, along with a few examples, were also written on the collaborative Miro board so the participants could consult the instructions at any time during the session.

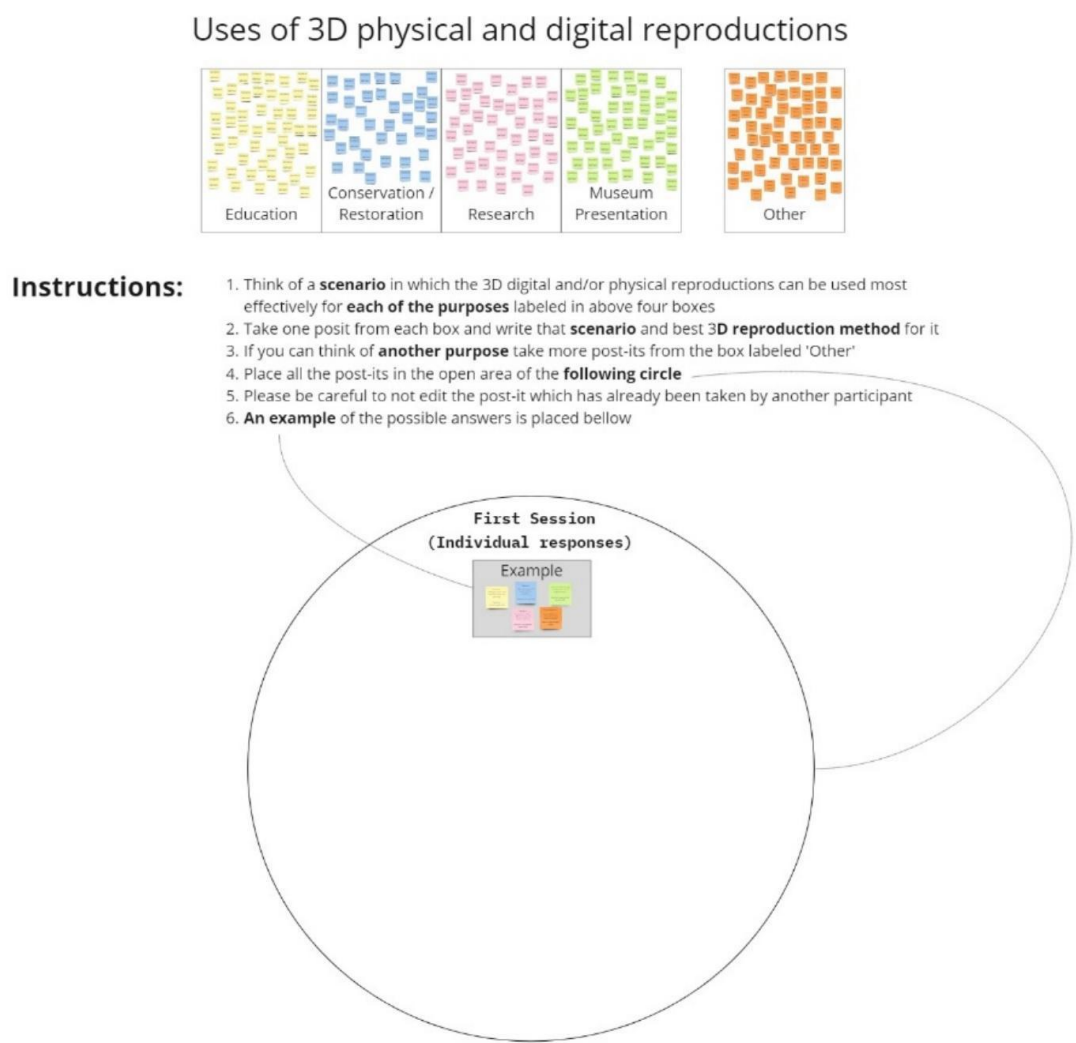

Figure 3. The collaborative board of the first session on Miro platform. The sticky notes representing different uses of 3D reproductions in five colors could be picked from the boxes at the top, filled and pasted in the empty space provided in the circular area at the bottom. The instructions for filling in the sticky notes are in the middle, along with an example of pre-filled sticky notes.

The second collaborative session lasted 55 minutes and consisted of discussions between the members of each predefined group about how to answer the research questions (section 1). Each group was assigned its own separate collaborative board in Miro (Figure 4), and all the members of each group were transferred to a breakout room in Zoom. This way, each group had a separate workspace and platform for discussion. The session questions were divided into two parts. One related to the use and design of 3D reproductions, and the other was more related to the authenticity of the experience (of the original) through such reproductions. Before the start of this session, the resulting sticky notes from the first collaborative session were displayed on the board of each group. Based on the different uses and scenarios proposed through the sticky notes, each group was asked to map their answer using the different templates provided. The use of the templates was not mandatory, and each group had the freedom to decide to use any format or pre-designed map to 
propose their answers. Similar to the first collaborative session, these instructions were written on the Miro board above the workspace and could be consulted during the session. All four breakout rooms in Zoom in this session were moderated by the three co-authors of this article and one collaborator. The role of the moderators was to clear up any uncertainties of the groups, record the conversations, and foster discussion among the group members.

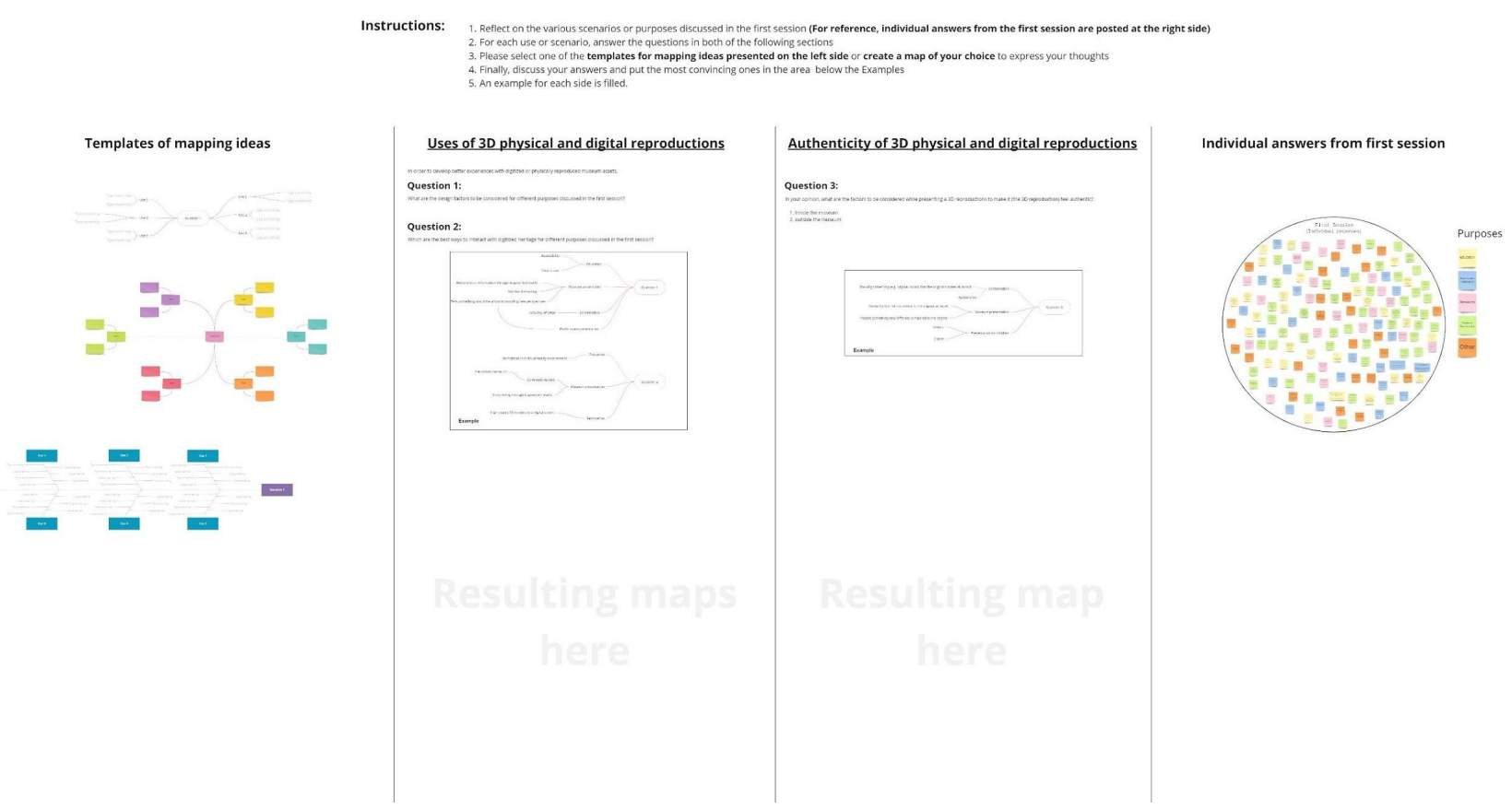

Figure 4. The collaborative board of the second session on Miro platform. Templates for mapping the answers to the research questions are provided on the left side while the middle space is for answering the research questions. The sticky notes resulting from the first collaborative session could be consulted from the left side. The instructions for answering the questions are provided at the top and an example of possible answers for each question is to be found in the boxes below the questions.

The plenary wrap-up session lasted 30 minutes. During this session, the representative of each group presented a five-minute summary of the discussions that occurred amongst the group members together with their results and conclusions formulated during the second collaborative session. Based on these group presentations, the participants were invited to ask questions and share their thoughts for the next 10 minutes. The session ended with a five-minute presentation in which the organizers provided an overview of the activities carried out during the workshop, the way results would be compiled, and how participants could contact the organizers if they had any further questions.

\subsection{Evaluation}

Using the existing literature together with the data collected through the workshop, both quantitative and qualitative data research could be carried out (Figure 5). The project resulted in four main sources of data: (1) the answers to the closed questionnaires; (2) sticky notes from the first collaborative 
session in which different scenarios and possible uses of 3D reproductions were described; (3) mind maps from the second collaborative session in which the participants' thoughts on the applicability of 3D reproductions for enhanced experiences were recorded; and (4) transcripts of the audio recordings of the conversations and discussions during the workshop.

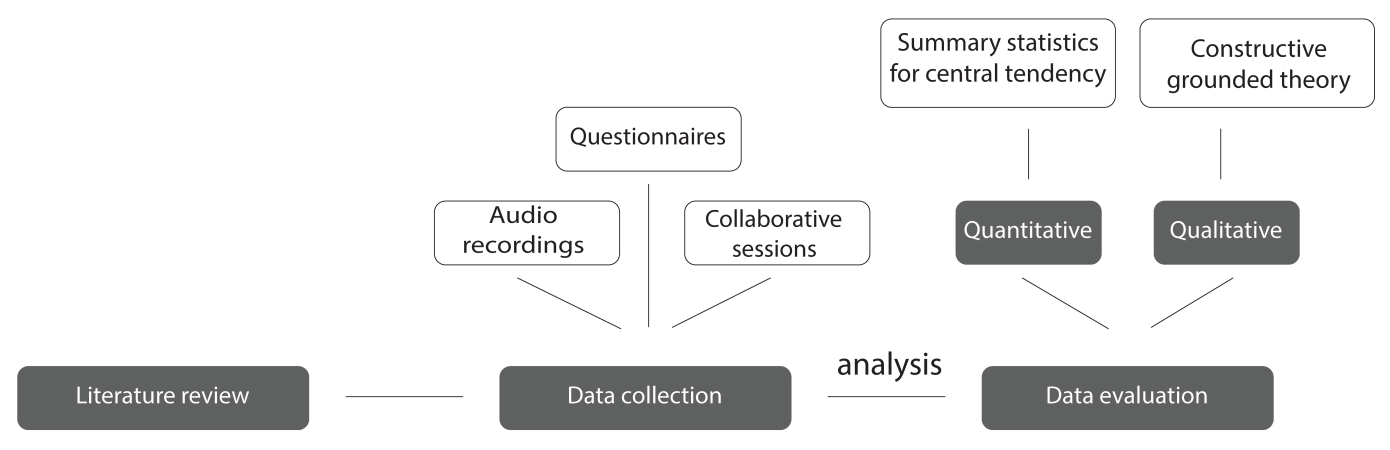

Figure 5. Data collection and evaluation pipeline.

\section{QUANTITATIVE ANALYSIS}

The data collected from the pre-workshop questionnaire and the first session of the workshop were analyzed using summary statistics for central tendency (mean, mode and median method). This analysis was used to partially answer the questions no. 1 and 2 of this research:

- How are the 3D reproduction methods under study perceived?

- In what way can 3D reproduction methods attribute to the experience of $\mathrm{CH}$ objects and artworks for museum education, $\mathrm{CH}$ research, conservation/restoration and museum presentation?

\subsection{Raw analysis}

\subsubsection{Questionnaire}

The questionnaire was presented to the participants $(n=24)$ before the workshop and consisted of 11 closed questions. Each participant was asked to rate the answers in a rage of 1 to 5,1 being the least effective and 5 being the most effective. The results of questionnaire responses presented here are based on the mean $(\mathrm{m})$ values and percentage of participant responses greater than or equal to $4(\geq 4)$ i.e. highly effective.

The majority of the participants considered the use of reproductions, whether physical or digital, (very) useful for a variety of art forms (sculpture, painting, architecture and ethnographic objects $(\mathrm{m}=4.18,79 \% \geq 4)$. Especially in the case of sculptures, the use of reproductions was considered very useful $(\mathrm{m}=4.46,92 \% \geq 4)$. Just as in the previous outcome when a majority of participants were convinced that reproductions were useful for various forms of art, they also considered the use of reproductions (very) useful for four purposes (education, research, preservation and presentation) $(\mathrm{m}=4.33,81 \% \geq 4)$, particularly when reproduction methods are used for educational purposes $(\mathrm{m}=4.58$, $92 \% \geq 4$ ). When asked about the use of 3D reproduction methods under study (AR, VR, digital screen 
displays and 3D printing) for different purposes, the majority of the participants considered all methods of reproduction effective for all four purposes $(m=3.83,65 \% \geq 4)$, especially $3 \mathrm{D}$ printing $(\mathrm{m}=3.94,69 \% \geq 4)$.

The participants were also asked about the effectiveness of reproductions: (1) in the presence of the original artwork; (2) in the absence of the original artwork, and (3) in the absence of the original artwork, but in the same setting (e.g., in two different museums). Most of the participants considered the second option most effective $(\mathrm{m}=4.13,75 \% \geq 4)$. Furthermore, the participants were asked how they would value different uses of 3D reproductions (as a one-on-one reproduction; showing alternatives of the original [e.g., colors, composition, texture]; the use of reproduction in a larger/smaller scale). The use of reproductions as a tool to show something different from the original (e.g., colors, composition, texture) was considered somewhat valuable $(m=3.75,63 \% \geq 4)$.

When asked about the effects of 3D reproductions on the perception of art, the participants thought 3D reproduction would impact their perception of the original artifact/artwork to a moderate/large degree $(\mathrm{m}=3.38,52 \% \geq 4)$. Of all reproduction methods, VR was considered the most impactful $(\mathrm{m}=3.63$, $67 \% \geq 4)$.

The participants were equally interested in using these technologies at home $(m=3.38,51 \% \geq 4)$ as they would be in a museum setting ( $m=3.38,50 \% \geq 4)$. Of all technologies, VR seemed to be the reproduction method that was the most preferred for use at home $(m=3.75,67 \% \geq 4)$. In the case of a museum setting, although the mean preference for AR was as high as VR, more participants preferred AR ( $m=3.58,63 \%$ $\geq 4)$.

\subsubsection{First plenary setting: sticky notes}

In total, there were 116 sticky notes that had been filled in, of which 41 were focused on museum presentation, 23 on education, 19 on research, 17 on other purposes and 16 on art conservation. Based on the sticky notes, in the case of museum presentation, the scenarios in which 3D technology seemed to be the most captivating were: immersion/simulating what it would be like to be in the setting of the artwork/time travel (6/41, AR/VR); depiction of artworks in different states/times in history (6/41, AR/3D printing); accessibility for the visually impaired and children (6/41, AR/3D printing); showing objects that have been lent (5/41, AR/VR/3D printing). Other scenarios revolved around the recreation of manufacturing processes, lost artifacts and original settings of artworks (9/41, AR/VR/3D printing). The most mentioned reproduction method was 3D printing (19/41).

In the case of education, the most recurring scenarios were: opportunity to compare distant sites/objects and remote interaction (8/23 AR/VR/3D printing); interaction with artworks (4/23, VR/3D printing); introduction of heritage to young children (4/23, Digital reproduction/3D printing/AR/VR); enhanced immersion/experiencing events (4/23, AR/VR). For education, the participants were of the opinion that all technologies were useful. The most mentioned technologies were AR \& VR (15).

For exploration and research related purposes, the participants mentioned two scenarios that were of primary interest: placing objects in their current/original location to get a better understanding of the original setting (4/19, AR/3D printing) and exploring different perspectives of existing heritage (e.g., polychrome, multiple versions, different shapes, different states of decay, different product design) (4/19, AR/3D printing). Other reoccurring themes and scenarios were focused on the 
materialistic qualities of artworks (e.g., the visualization of hidden elements, manufacturing process) (6/19 AR/3D printing/Digital reproduction). 3D printing was most often mentioned (12/19).

Analyzing the sticky notes concerning 3D technologies' utlity for conservation purposes revealed four major themes: replacement of missing parts (3/16, 3D printing); the recreation of original state and colors (3/16, 3D printing/AR/VR); documentation of current material state/status report/entire collections (3/16; digital reproduction/3D printing); discovering inaccessible/damaged sites (3/16, AR/VR). For this purpose, all technologies were mentioned. However, again, the most mentioned technology was 3D printing (11/16).

Amongst the sticky notes with "other" there was a variety of answers, yet, there were two scenarios that were both mentioned four times: public awareness (AR/VR/3D printing) and marketing: attracting visitors/ selling replicas (AR/VR/3D printing). The opportunity of showing works of art in their original context and creating a more immersive experience were also mentioned as important opportunities for the use of these technologies (6/17). Other scenarios mentioned were: art market (viz., visualizing how art would look in one's home or gallery); physical therapy, and security training and training people how to transport artworks. Of all the technologies, VR was mentioned most often $(12 / 17)$.

Overall, based on the sticky notes, 3D printing (68/116) seems to be the most preferred reproduction method for all purposes, followed by AR (55/116), VR (53/116) and digital screen displays (11/116).

\subsection{Discussion}

The evaluation of quantitative data about applications of 3D replicas presented here is based on the collective perception of all participants without analyzing their data individually on a personal or professional level.

Overall, the majority of the participants considered the use of reproductions (either physical or digital) (very) useful for all of the purposes included in this research (education, research, conservation/restoration, and museum presentation). 3D printing was seen as a more appropriate method for museum presentation than were digital reproductions, AR, and VR. The latter were considered especially valuable for more explorative and research-driven purposes. Nevertheless, the participants thought that the use of reproductions can add value to the original whether present or not. The use of reproduction technologies was seen as most useful when the original artwork is not in the presence of the reproduction or near the reproduction. For the use of reproductions, it appeared that the participants saw the most potential in reproductions that show something different than the original (e.g., colors, composition, texture). In regard to these technologies' effect on perception, the participants agreed that 3D reproduction could impact their perception of the original artifact/artwork. Of all methods, 3D printing was considered the most impactful. As for the setting, the participants were as interested in using these technologies at home as they would be in a museum setting. At home, the participants preferred reproductions using VR, while AR was preferred in a museum setting.

Furthermore, in the case of museum presentations, the possibility of immersion and the capability of showing what it would feel like to be in the setting of the artwork, the depiction of artworks in 
different states/times in history and accessibility for blind people and children were seen as the reproduction technologies' most interesting side benefits. Also, for education, immersion was seen as an important asset. The opportunity to compare distant sites and objects, the possibility to promote remote interaction and the opportunity of introducing heritage to young people was also seen as a welcome extra benefit of reproduction technologies. Regarding exploration and research, there were two recurring scenarios: placing objects in their contextual/original location and the exploration of different perspectives of existing heritage. Analyzing the results for using technology for conservation purposes showed that the technologies were regarded most useful for replacement and recreating missing or damaged elements of $\mathrm{CH}$ objects and as a tool for material documentation. Additionally, the technologies were regarded as useful for stimulating public awareness, either as a tool for people to better comprehend the fragility of $\mathrm{CH}$ or as a tool for museums and cultural institutions to promote their collections and ethos. Overall, 3D printing appeared to be the most preferred technology for all purposes.

\section{QUALITATIVE ANALYSIS}

While quantitative data can be used for descriptive overviews or for testing hypotheses, qualitative data can provide a richer understanding of quantitatively measured data. In social sciences, Grounded Theory (GT) is a popular qualitative research method. It allows one to collect data from a variety of sources such as interviews, focus groups, group discussions and participant observations. Data are co-constructed by the researchers and participants under study and coded by the researchers' perspectives, values, privileges, positions, interactions and geographical locations [Charmaz 2009].

Mainly applied to social sciences, GT has gained wide acceptance in various other domains. Specifically, within Human-Computer Interaction (HCI), GT has been found to provide qualitative insights in understanding how usability issues are subjectively and collectively experienced and perceived by different user groups [Adams et al. 2008]. Moreover, several problems in User Experience Design areas are likely to have few existing theories to fall back upon and the context in which the experiences occur plays a crucial role. GT can be a potent tool for generating new knowledge [Khambete and Athavankar 2010].

In order to comply with this study's aim of getting insights into designing and enhancing experiences with 3D technologies and to evaluate the perception of these $\mathrm{CH}$ reproductions, we adapted a simplified approach drawn from GT to analyze the qualitative data collected during the collaborative sessions. The data were collected through mind maps and recordings of the conversations. These were analyzed through a constructivist GT approach [Charmaz 2014]. Insights gained from the literature review, transcription of audio recordings of participant discussion during the workshop and mind maps from each group of participants during the second collaborative session were analyzed by this approach (Figure 6).

The analysis started with individual memo writing, which involves writing down thoughts, feelings or questions that arise from the analytic process by two researchers separately (the first two authors of this article). Subsequently, the memos were analyzed by coding based on the relevancy of concepts 
and similarity between them. As different groups approached the same questions in unique ways, the analysis was made in context i.e. the background of the participant and the groups.

During the data coding phase in a qualitative evaluation, properly dealing with inter-rater reliability is highly recommended to avoid a large influence on the quality of data evaluation by researcher's biases [Armstrong et al. 1997]. Therefore, key concepts implicit in each of the groups were articulated and refined simultaneously by two researchers working in isolation from each other. Finally, their results were compared in order to pinpoint the most prominent concepts and themes.

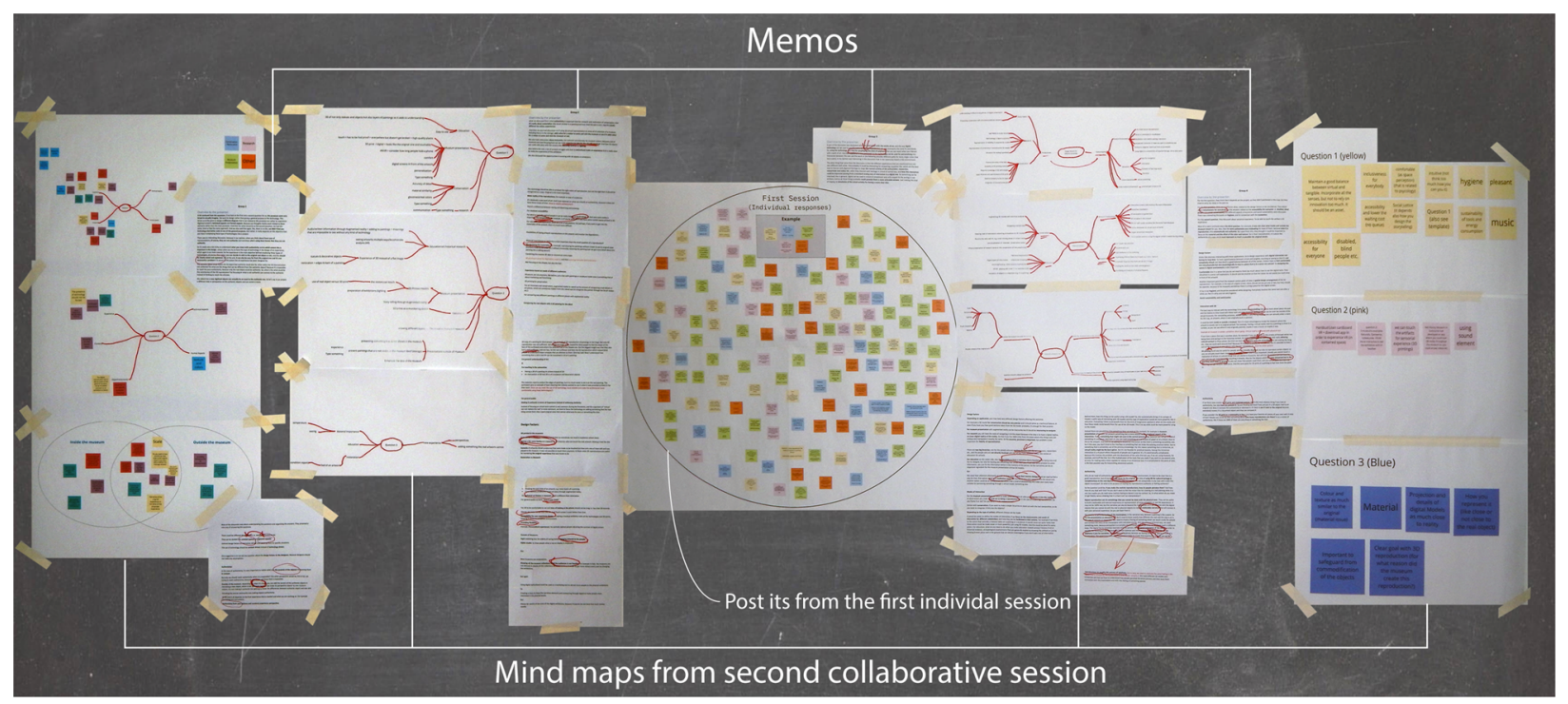

Figure 6. Analyses of the qualitative data from collaborative sessions through Grounded Theory.

\subsection{Overview of group discussions}

This section reflects upon the observed differences among the four groups in ways of understanding and approaching the same questions. These observations were later used to draw the evaluation criteria from data in context (section 6.2).

\subsubsection{Understanding of questions}

The group of designers spent considerable time trying to understand the broader purpose of the questions. It was concluded by them that it was preferable to focus on a specific design goal instead of giving technology a general purpose, since the design of technology depends largely on objective factors. The group of engineers and museum professionals, on the other hand, approached the questions more directly, proposing different solutions to create better experiences with the 3D technologies for all stakeholders. Lastly, the group of visitors understood the questions related to experience design instantly but were thrown off by the question of authenticity. Overall, the concept of authenticity was much discussed in all the groups. They interpreted it in two ways: it could refer to the authenticity of the copy or the authenticity of the experience. 


\subsubsection{Approach to answering questions}

When answering the questions, instead of using a template, the group of designers proposed their own diagram based on the context for the use of technologies and the way the technical aspects and formal aspects of technologies should and could comply with this. The group of visitors approached the questions similarly and did not use a template either, but they wrote their ideas on sticky notes. On the other hand, the group of cultural heritage professionals and engineers did position their answers in the templates. According to the group of engineers, the applications under discussion differed from one another. Therefore, the way they answered the questions was by imagining the best ways to interact with $\mathrm{CH}$ objects presented via these different reproduction methods. Here, they made a distinction between policymakers, researchers, conservators and visitors. They analyzed how the different interactions with objects could be improved by shifting from an analogical way of handling objects to a digitalized/physically reproduced way. In general, they argued that (digital) reproductions are complementary whilst respecting the integrity of the "analogue" real artifacts.

\subsubsection{Observations from discussions}

The group of designers considered different design factors ranging from aesthetics to function. They proposed several factors that should be kept in mind not only for designing experiences with objects but also for designing and managing the 3D content. As for the question related to interaction, they, as well as the group of heritage professionals and the engineers, asserted that the technologies and modes of interaction used should be developed based on the needs of the users. Here, when discussing the authenticity of experience, they discussed authenticity from a user (visitors and curators) experience perspective. Somewhat similarly, the group of engineers thought that modes of interaction to a large extent revolve around the interaction with physical 3D reproductions; hence their emphasis on authenticity in terms of art's materiality.

In contrast, the discussion among the group of visitors was more focused on the general needs of the visiting public without aiming at design factors specifically. They approached this topic of interaction by relying on their past experiences in museums. In terms of authenticity, like the engineers, they put the most emphasis on physically 3D printing materials and textures.

\subsection{Criteria for evaluation of experience based on group discussions}

The following section, grounded in the data collected from participants, is an attempt to answer question no. 3 of this project ("what are the design factors to be considered in order to develop enhanced experiences and interactions with 3D digitized and printed $\mathrm{CH}$ objects in a museum setting?"). The qualitative analyses of the data collected from the four groups were based on their expertise and resulted in devising a number of evaluation criteria for designing experience, 3D interaction and authenticity.

\subsubsection{Designing 3D cultural experience}

User experience can be considered as the sum of three factors: users' context, the characteristics of the designed system and the context within which the interaction occurs [Hassenzahl and Tractinsky 2006]. The analysis and comparison of conversations between different groups during 
the workshop unveiled that these three design factors are equally important for designing experiences with 3D reproductions (Figure 7).

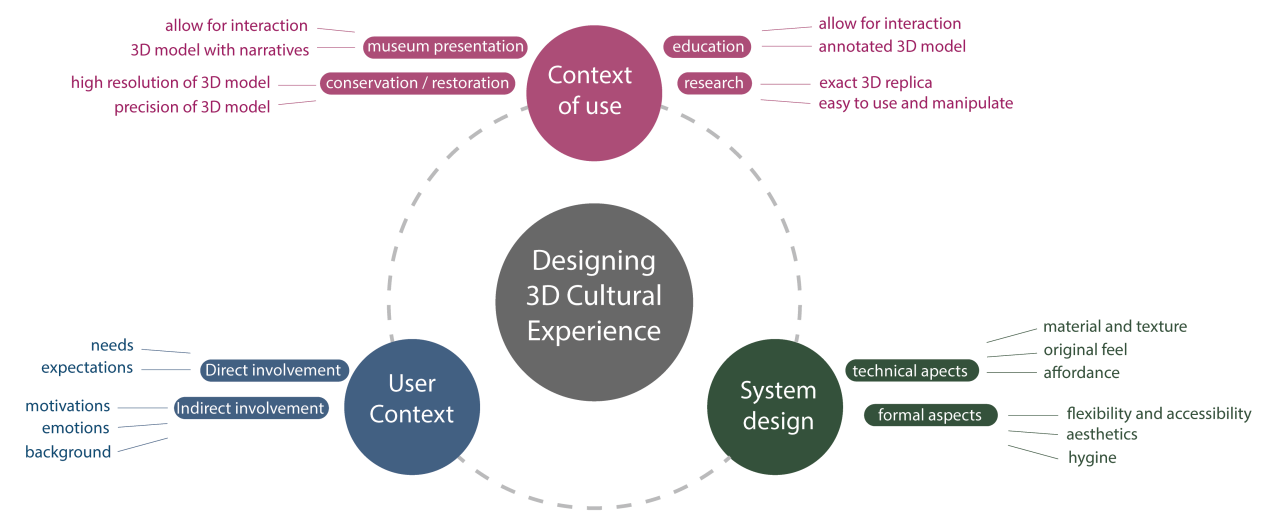

Figure 7. Design factors for 3D cultural experience based on evaluation of qualitative data.

Firstly, the context of use was considered paramount in deciding which technologies are or will be used. A 3D model used for conservation purposes should serve as technical support for the artwork, thus should be very precise and highly detailed. In this case, a fraction of the original artifact, but in a high resolution, is considered more useful than a large-scale model at a lower resolution. For this reason, the high-quality AR model was considered very useful for preservation-related purposes. It can accelerate the process of recognizing small details in art hidden to the naked eye (e.g., recognizing painters' styles through brushstroke analyses or looking into painting samples of different layer buildups). In the case of research-related goals, the 3D model must represent an exact digital replica of the real object that is easy to use, so that even if the researchers are physically apart from the actual $\mathrm{CH}$ site or object, they are still able to analyze and manipulate them as if they were handling the actual object. For museum presentation, on the other hand, precision of the reproduction is not crucial; therefore, a large-scale model at a lower resolution presented with additionally connected narratives was considered to be the most appropriate. It is worth mentioning that museums are not closed spaces presenting their art only inside fixed exhibition spaces, but they have franchises reaching far beyond their physical walls. 3D reproductions can be helpful in designing different strategies in order to bring art to the public [Rijks Museum 2020]. In this way, by using 3D technologies before or after the museum visit, museums could attract more people to the actual physical exhibitions in the museum. Here, people's interests could be triggered by letting them interact with art through reproductions. For education purposes, the annotated 3D models that can be interacted with on a digital screen were considered highly effective. In brief, the experience must be content- not technology-driven.

Secondly, based on the analysis of collaborative sessions, the target groups for designing experiences with 3D models can be divided into two branches: people working directly with the physical work of art or heritage objects (e.g., restorers, researchers, art historians); people not directly involved with art (e.g., museum visitors, educators in schools or in museum education units). These two groups have different needs, and the experiences must be designed to comply with these needs. In the case 
of conservators, researchers, and art historians, exact replication of the artwork is essential. For visitors, 3D models should not just be representative but should also provide an addition such as a narrative that is, above all, functional, easy, fun to navigate and engaging. This could be done, for example, by focusing on triggering emotions or memories when providing information that is being taught. Moreover, the 3D reproduction methods should be self-explanatory. In this way, confusion and the feeling of being overwhelmed can be avoided, hence saving time whilst securing the efficacy of the learning process. Furthermore, especially within a museum setting, spatial arrangement and the careful curation of visitor-streams are of utmost importance when considering the use of 3D reproductions. For example, in an exhibition with digital screens, it often happens that there is a long queue of visitors that are waiting to use them. Here, considerations could be made on installing more screens or re-routing the visitors to other parts of the exhibition to avoid crowding.

Thirdly, apart from formal aspects for system design (e.g., aesthetics, hygiene, flexibility and accessibility), technical aspects of designing the experience were prioritized. It appeared that 3D reproductions - especially 3D prints - can contribute to an extra dimension for the visitor: touching artifacts. By giving the general public the possibility to touch the artwork through 3D printed replicas, we can evoke the same feeling as experienced by restorers or art historians who can touch the real artwork on a daily basis, making it possible to come closer to it and its creator than ever before. In this case, for reproductions to be effective, they should not only look like the original, but most and foremost, should feel original: the print's texture, temperature, shape, and weight should be similar to that of the original. For example, in Boijmans van Beuningen's Sgrafitto in 3D exhibition [Museum Boijmans 2009], 3D printed reproductions of plates were placed in front of the original artifacts, giving the visitors the opportunity to experience the original artwork. On the other hand, technologies using digital 3D replicas must be made comprehensible for users by carefully designing the affordance of digital applications. Such applications must be easy to use also for professionals (who are mostly reluctant to use new methods instead of the traditional techniques) for creating reliability.

\subsubsection{Interaction with the digitized artifacts}

When asked about the modes of interaction with 3D replicas (3D printing, AR, VR, digital screen displays), all groups asserted that the interaction tools must be selected based on the needs of the stakeholders and the goals of the museums (see section 2) (Figure 8).

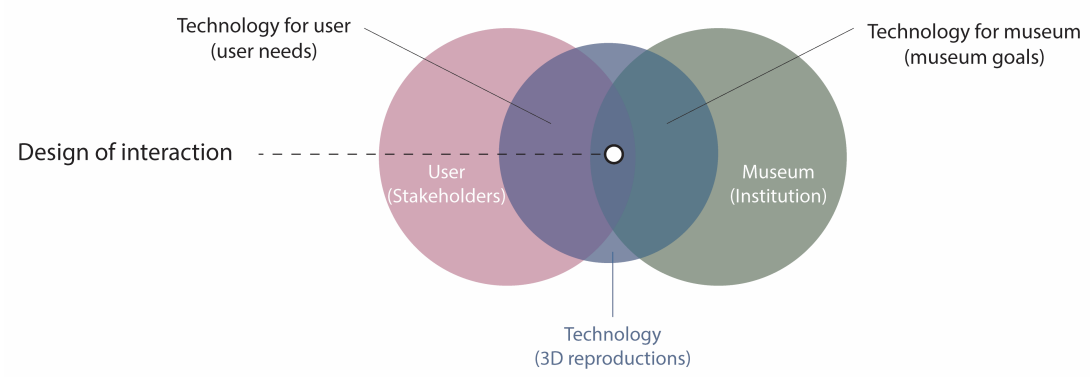

Figure 8. Criteria for interaction with 3D replicas of $\mathrm{CH}$ based on evaluation of qualitative data. 
In terms of interaction with users, the details of each case makes it hard to determine in advance the efficacy of 3D reproduction methods. Clearer to define, however, is approaching the way 3D technologies can facilitate the day-to-day practice of stakeholders that interact with $\mathrm{CH}$ objects. For example, interactive 3D models could support restorers and researchers to make material analyses easier and faster. Such simple interaction can be created by using a digital screen display.

A similar approach can be adapted for other purposes. Questions that can be asked for instance, for education is to what extent 3D reproductions can contribute to what is being taught? For restoration: should 3D printed parts stand out within the lost composition, or should they be fully integrated into the context? In the case of museum presentation, one must make decisions based on the objective of showing a reproduction, which will determine to what extent a reproduction should stand out as being a reproduction. For museum visitors, the most effective way of creating interaction with 3D technology is to narrate stories that provide a more profound dimension to the museum experience that offer something new. For example, using VR makes it possible to generate a sense of time travel and linking this to the museum's collection. Although this method can be used both inside as well as outside of the museum, it is advantageous inside of the museum where the artwork is mostly not in its original context but still provides a tacit link between visitor and artwork. In the history of art, historical evidence or archaeological environments are generally explained by showing the artifacts in $2 \mathrm{D}$ or by showing fragments (e.g., a shard from a vase) or fragmented information. Here, 3D reproduction could be useful to add three-dimensionality, but it can also contribute to the object's context (e.g., showing the shard within the entire shape of the vase). AR applications were considered most suited for these digital interactions with physical objects.

Apart from the users' perspective, the participants agreed that 3D technologies are mainly interesting for museums as tools to offer possibilities for doing something that is impossible in physical reality. For example, museums can create emotional interactions with the visitors, something that might not exist in the normal presentation with a label next to the presented artwork. In this case, museums need not create interactions that can make the existing practices better, but can offer something new and completely different from previous experiences. For this reason, something that is immersive like VR was considered to be the best option. Yet, it was mentioned that for practical reasons, it could be complicated using VR in a museum with thousands of visitors on a daily basis. Furthermore, the use of headsets in museums can create problems of hygiene or financial concerns for the multiplication of the tools that are needed for every visitor to interact in an immersive way.

Furthermore, including physical 3D printed reproductions and the option for the visitors to touch them can contribute to making museum content more accessible to a wider audience (e.g., blind or partially sighted people). As mentioned before, here, materiality is important and a hurdle to be overcome as the 3D print's plastic or resin does not come near the materialistic feel of a marble statue. For instance, one of the participants mentioned that using 3D reproductions for blind or partially sighted people is tricky as a replica alone is not sufficient. In a workshop held in 2015, paintings by van Gogh were presented amongst spectral maps and a real sunflower for people to feel the shape of the sunflowers. Only in this way did the 3D reproduction contribute to helping blind people understand these abstract artistic concepts. Besides its potential usefulness for aiding visually impaired people, touching a work of art also adds the possibility of seeing and touching artistic or cultural objects that are inaccessible, too fragile to display, being restored or stored in 
museum depots. With 3D printing, museums can have an exact facsimile to help show how these objects were originally used, and visitors can actually have something approximating the "original" experience by touching them. The same goes for 3D printing fine art such as paintings. Feeling different layers of a painting can contribute to understanding the artwork's dimensions and the artist's techniques.

\subsubsection{The authentic experience}

Authenticity is a complex and heavily debated concept within the field of art and cultural heritage, especially since the ICOMOS' NARA document on authenticity was published in 1994 in response to the need to better define this idea [UNESCO et al. 1994]. Nowadays, "authenticity", as seen from a Western perspective, could be described as something that has the quality of being authentic, original, or genuine [Latour and Lowe 2012]. It refers to something that is genuinely made or done in a traditional way that faithfully resembles an original based on reliable facts [Tissen 2020]. With the term authenticity, one often refers to the material of the original artwork as the only provider of the true traces of the past and a connection with the artist. However, in the same text and in other recent studies on the authenticity of $\mathrm{CH}$ objects and the interference of 3D technologies, it became clear that authenticity does not solely rely on singular and static materialistic qualities of art, but rather relies on a complex system of contextual and conceptual meaning and significance granted to the object. The material of an object, together with these different perspectives, creates the irreplaceable value of an artwork, its authenticity [Jones et al. 2018; Jensen 2018]. The latter appeared to be the perception of authenticity among the groups under study: they agreed on the need of defining the term "authentic" or "non-authentic" in a contextual way instead of emphasizing the materialistic qualities of $\mathrm{CH}$ artifacts; hence the material/visual similarity of the replica (Figure 9).

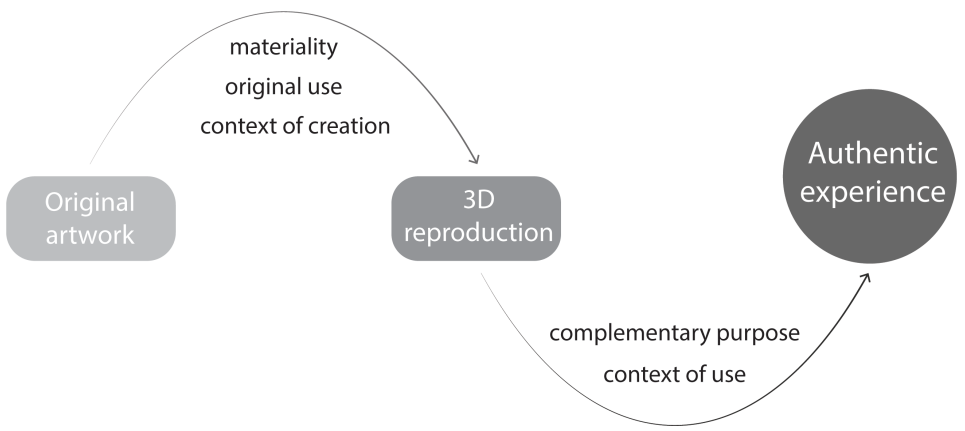

Figure 9. Criteria for authentic experience of 3D replicas of $\mathrm{CH}$ based on evaluation of qualitative data.

Additionally, when presenting a 3D reproduction, it was considered essential for the reproduction to be of good quality and as identical to the original as possible. Consequently, in order to avoid confusion, it was said to be important to clearly state that it is a facsimile, as 3D reproductions should always be complementary to the real objects; hence reproductions cannot be compared to their original source. Here, in terms of design, it has become clear that the decisions must be made based on balancing two things: the extent to which we make a high fidelity reproduction and, at the same time, demonstrating that it is actually a copy. Furthermore, according to the participants, 
authenticity is experienced in multiple ways through our senses: there is a clear difference between seeing, touching, observing and knowing. Material resemblance or similarity was more often considered important than the visual qualities of the reproduction. Consequently, when designing a reproduction, there are choices that can be made based on either the visual likeness or the "textural/tactual" similarity of the reproduction, depending on the purpose of the reproduction and the specific characteristic of the original it is designed to highlight or enhance. Different technologies have their different effects. A 3D print in plastic, for example, never truly resembles the materiality of original object. However, when considering the use of digital reproduction methods (AR, VR and digital screen displays), the materiality of the object can not only be reproduced, but also be manipulated: for example, reproducing the paintings without a layer to see its original state (incisions made by the artist etc.) by reconstructing every layer of a painting. In this way, although the materiality and feel of the artwork are not directly physically presentable, the 3D technology provides a new way of playing and interpreting the visual and material authenticity of the original object. The importance of authenticity of the artwork and material, visual or contextual qualities of reproduction in this sense depend largely on purpose for making and using a 3D reproduction.

When considering the use of reproduction for conservation and research-related purposes, the emphasis is placed on the authenticity of the artwork's material qualities. In this sense, the material feel and appearance of 3D reproductions should remain close to that of the original objects and the feel of those objects. Here, it was said that a reproduction can be visually different, as long as the material feel of the reproduction resembles that of the original. That way, a 3D print would be the most efficient for this purpose as it is the only technology that conforms with the necessity for a material authentic experience.

In contrast, when using 3D reproductions for education and museum presentation, the focus on authenticity and the role of the reproduction shifts drastically. Whereas it is important for conservation and restoration specialists to remain close to the genuine material of the object (and thus the reproduction), the focus for education is more related to the representation of context and different perspectives, both intangible qualities of art. For the general public, the focus should be on achieving the experience of authenticity rather than similarity of material. Furthermore, instead of focusing on mimicking and reproducing experiences that can already be done in reality (e.g., visiting museums via virtual tours), the visitors said reproductions are more useful for creating a complementary non-existing experience that is otherwise not possible with the original object, context or (museum) setting. Here, it becomes clear that the importance granted to conceptual and contextual authenticity is key when considering the use of art reproductions. The participants argued that these technologies can be used to create narratives that connect with visitors' personal experience in ways that are educational, emotional or intellectual, as long as they enhance the idea and relationship between the visitor and the work of art. Unlike the cases of reproductions used in restoration or research, pointing out the exact difference between the real and the copy is not as important in museum presentations or education. Therefore, 3D reproductions need not be as visually or materially similar. What is essential, however, is creating individual narratives that are authentic to one's personal experience. Yet, this is hard to achieve using solely one reproduction technology, since different people perceive aesthetic works in different ways and have their own set of memories. 
To create experiences that conform to individual needs and thoughts, different 3D models, technologies and immersive sets should be adopted. In the case of authenticity and the role of reproductions in this regard, we have to understand how people perceive the entire process between artwork, (museum) visit and reproduction for them to stay connected to the masterpiece. This can take place both inside as well as outside the museum, both having different effects. Here, In the case of using 3D reproductions in museum spaces, the use of physical 3D reproduction was considered most effective when it would be demonstrated next to the original artwork, because it helps in making comparisons with the original. Here, a direct encounter between original and reproduction was thought to enhance the connection between visitor and art the most, since the museum space itself does not provide any other contextual information about, for instance, the creative process. Outside of the museum, however, other factors are at stake. Depending on when the original object was made, we can present the original object through reproductions near the owners of the authentic objects or their creators, or artworks can be placed in the original building or studio where it was once made. Here, it is not about making a material authentic object or reproduction, but the focus is on getting to know the creative process. The source community can be involved in making objects authentic in terms of experience. Eventually, it all depends on the final experience that is needed and what output a certain project aims at, which is decisive in the choice of the reproduction method to express these aims and the way it is designed. Different perspectives, purposes and motives determine the authenticity of the experience and the reproduction. On the whole, the participants agreed that reproductions are especially useful for (re)creating context and intangible experiences. They were considered important for meaning-making and offering new perspectives, enhancing the connection between people and the material work of art and creating new valuable meanings of these objects in society.

\section{CONCLUSION AND FUTURE WORKS}

This research aimed to get a better understanding of the applicability of various 3D reproduction methods (AR, VR, digital screen displays and 3D printing) for different purposes (education, research, conservation/restoration and museum presentation), and to fathom the perception of these technologies. The questionnaire and the results of the discussions among the stakeholders in the workshop revealed that although the participants from different groups have very diverse ways of approaching the questions asked, the majority of the participants that took part in this research considered the use of reproductions (either physical or digital) (very) useful for all of the purposes included in this research.

\subsection{Conclusions}

When designing the experience using these reproduction methods, it became clear that the quality of the experience depends on three main factors: users' context (background, needs, expectations, motivations, emotions), the context of use (why these methods are being employed) and on design of the system (both formal and technical aspects of the system in which users interact with the technologies). Subsequently, this also influences the modes of interaction between users and 3D reproductions. The analyses of collaborative sessions revealed the importance of developing modes of interaction based on the needs of end-users (what they expect from a specific technology) and the 
museums' goals (how a specific technology can enable museums to reach more people). Lastly, although there is a lot of confusion about the term authenticity and its significance, it was a topic of great importance when 3D reproductions are brought into play. It is evident that a reproduction cannot obtain the same material authenticity as can the original work of art, yet the use of 3D reproductions illustrated the importance of the original purpose of the objects, the context in which they were created, and their conceptual meaning. Albeit a reproduction cannot exactly correspond to the original, it appeared that for the perception of reproductions realism and similarity to the original was still highly desirable. The participants all agreed that they did not want to be misled by a reproduction, yet it should have a realistic feeling to it in order for the reproduction to blend it into the context and mean something in reference to the original. In this regard, for an authentic experience, the decisions must be made based on the extent to which we make it high fidelity versus demonstrating that it is actually a copy.

\subsection{Limitations and future research}

As this study was exploratory in nature, it is evident that not everything could be included at once. One obvious limitation is the fact that we could not provide any insight in the specifics of the perception of art and authenticity of the individual participants. Our focus was not specifically on the difference in the demography of the participants. What would be interesting for future research is to make a comparison between the perception of art and its authenticity between groups of different ethnic backgrounds, ages, and perhaps even gender.

Another limitation can be found in the fact that this study only used a few forms of art. Further investigation will be done by doing more profound research into the reproduction of different forms of art. In the future, research will be done on the perception of various reproduction techniques in the case of easel paintings. Using this research as a starting point, the comparison of the perception of easel paintings to the experience of the more three-dimensional case studies used here could be useful in understanding the effects of 3D reproductions of individual art forms.

Furthermore, due to the pandemic, it was not possible to host the sessions on-site. This meant that the participants could not see the reproductions in real life nor could they freely interact with and touch the replicas. This might have influenced our results. For this reason, in the future, we are planning on similar sessions but on-site. Lastly, the authors would like to continue this research by specifically focusing on the experience of these technologies for museum visitors with none or only limited prior knowledge of these 3D methods and within a museum setting. We have planned researching this by organizing and conducting interviews on-site at the Rijksmueum in Amsterdam. The Rijksmuseum in Amsterdam has a life-size reproduction of The Laocoon Group before which the perception of representations of the statue via different means of 3D reproduction methods will be investigated in the near future.

\section{REFERENCES}

AdAMS, A., LunT, P., AND CAIRNS, P. 2008. A qualitative approach to HCI research. In: P. Cairns and A.L. Cox, eds., Research Methods for Human-Computer Interaction. Cambridge University Press, Cambridge, UK, 138-157. 
Armstrong, D., Gosling, A., Weinman, J., And Marteau, T. 1997. The place of inter-rater reliability in qualitative research: An empirical study. Sociology 31, 3, 597-606.

CECA. 2014. ICOM Education 25 - Change of Perspective (New) ideas for representing museum objects. .

CHARMAZ, K. 2009. Shifting the grounds: Constructivist grounded theory methods. Developing Grounded Theory: The Second Generation, 127-154.

CHARMAZ, K. 2014. Constructing grounded theory. sage.

Freeman, A., Adams Becker, S., Cummins, M., McKelroy, E., Giesinger, C., And YuhnKe, B. 2016. NMC Horizon Report: 2016 Museum Edition. Austin, Texas.

HASSENZAHL, M. AND TRACTINSKY, N. 2006. User experience - A research agenda. Behaviour and Information Technology 25, 2, 91-97.

JENSEN, P. 2018. Evaluating authenticity: the authenticity of 3D models in archaeological field documentation. In: McDonald Institute.

Jones, S., JefFrey, S., MAXWELl, M., HALE, A., AND JonES, C. 2018. 3D heritage visualisation and the negotiation of authenticity: the ACCORD project. International journal of heritage studies 24,4 , 333-353.

Khambete, P. And Athavankar, U. 2010. Grounded Theory: An Effective Method for User Experience Design Research. Design Thoughts, 11-24.

Latour, B. And Lowe, A. 2012. The Migration of the Aura, or How to Explore the Original through Its Facsimiles. In: T. Bartscherer, ed., Switching codes: thinking through digital technology in the humanities and the arts. University of Chicago Press, Chicago, 1-18.

Micoli, L., BARSANTI, S.G., MALIK, U., AND GUIDI, G. 2018. 3D data integration for the digital reconstruction of cultural heritage monuments. IOP Conference Series: Materials Science and Engineering 364, $1,1-8$

Museum Boijmans. 2009. Sgraffito in 3D. Museum website. https://www.boijmans.nl/en/exhibitions/sgraffito-in-3d.

RIJKS MUSEUM. 2020. Experience the Night Watch. Museum website. https://beleefdenachtwacht.nl/en.

TiSSEN, L.N.M. 2020. Authenticity vs 3D reproduction: Never the twain shall meet? Arts in Society. Academic Rhapsodies, Leiden University Centre for the Arts in Society, 21-40.

UNESCO, ICOMOS, AND ICCROM. 1994. the Nara Document on Authenticity. . 